\title{
ERICA: A multiparametric toxicological risk index for the assessment of environmental healthiness
}

\author{
Elena Boriani*, Alessandro Mariani, Diego Baderna, Cinzia Moretti, Marco Lodi, Emilio Benfenati \\ Laboratory of Environmental Chemistry and Toxicology, Istituto di Ricerche Farmacologiche "Mario Negri" (IRFMN), 20156 Milan, Italy
}

\section{A R T I C L E I N F O}

\section{Article history:}

Received 11 January 2010

Accepted 29 April 2010

Available online 9 June 2010

\section{Keywords:}

Risk index

Pollutants

Ecotoxicity

Human risk assessment

Environment

Integrated strategy

\begin{abstract}
A B S T R A C T
A risk assessment strategy considering the impact of chemicals on the whole ecosystem has been developed in order to create a sound and useful method for quantifying and comparing the global risk posed by the main different hazardous chemicals found in the environment. This index, called Environmental Risk Index for Chemical Assessment (ERICA), merges in a single number the environmental assessment, the human health risk assessment and the uncertainty due to missing or uncertain data. ERICA uses a dedicated scoring system with parameters for the main characteristics of the pollutants. The main advantage is that it preserves a simple approach by condensing in this single value an analysis of the risk for the area under observation. ERICA quantifies and compares the global risk posed by hazardous chemicals found in the environment and can be considered a diagnostic and prognostic method for environmental contaminants in critical and potentially dangerous sites, such as incinerators, landfills and industrial areas or in broader geographical areas. The application of the proposed integrated index provides a preliminary quantitative analysis of possible environmental alert due to the presence of one or some pollutants in the investigated site.

This paper presents the method and the equations behind the index and a first case study based on the Italian legislation and a pilot study located on the Italian seacoast.
\end{abstract}

(C) 2010 Elsevier Ltd. All rights reserved.

\section{Introduction}

Many risk indicators, priority systems and schemes to screen chemicals for potential adverse effects once released into the environment have been published. Several indicators have been applied in various countries, with different goals and methods (DEFRA, 2006; SCRAM (Snyder et al., 2000); Senese et al., 2010). A number of research organizations started exploring the state of the art of risk indicators, in particular for pesticide risks, to examine the

Abbreviations: AQI, Air Quality Index for air macropollutants; BCF, bioconcentration factor; EF, Environmental fate; EFI, Environmental Fate Index; EQ, Ecotox Quality Index; EQI, Ecotoxicological Quality Index; ER, Exceeding Risk; ERI, Environmental Risk Index; ERICA, Environmental Risk Index for Coupled assessment; ERIE, Environmental Risk Index and Exceeding value; HC, Cancer Risk Index; HCR, Human Cancer Risk; HQ Human Quality Index; HTI, Human Toxicological Index; ITE, Integrated Threshold Exceeding; NEP, number of pollutants exceeding risk threshold; NIC, number of investigated priority compounds; NOEL, No Observed Effect Level; PEC, Predicted Environmental Concentration; PI, Pollutant Risk Index; PNEC, Predicted No-Effect Concentration; SRI, Substance Risk Index.

* Corresponding author. Via Giuseppe La Masa, 19-20156 Milano, Italy. Tel.: +3902 39014 564; fax: +390239014 735.

E-mail address: elena.boriani@marionegri.it (E. Boriani). outcome and limitations of different approaches and harmonize the use of these indicators internationally (USEPA, 1989, 1997, 2004, 2005; Huijbregts et al., 2000; RIVM, 2003; EUSES, 2008; USEtox, 2008; OECD, 2009). However, at present these global indices are not able to produce a single value for the potential risk of compounds to humans and the environment on a local scale for each individual ecological compartment (water, soil, sediment and air).

The need is first of all to provide clear information to regulators and population about the possible hazards in a site and the relative effects on the health status. The challenge is that a global index must cover every environmental compartment and must be based on detailed scientific meaning behind each hazard calculation. To face this challenge we have developed the Environmental Risk Index for Chemical Assessment (ERICA). Each element that composes ERICA has a sound scientific basis derived from updated guidelines and scientific data, merged in a single value within an innovative relationship. The main idea behind ERICA is to get a comprehensible picture of the general situation of a critical area; this is useful for detailed risk analysis of potentially dangerous compounds and for comparisons in time and space. ERICA starts from an evaluation of the single compound overall risk (SRI, Substance Risk Index) (see Fig. 1), extends it to all compounds and then assesses the entire chemical load for a specific territory. In the context of risk assessment, ERICA can be considered as a diagnostic and prognostic 


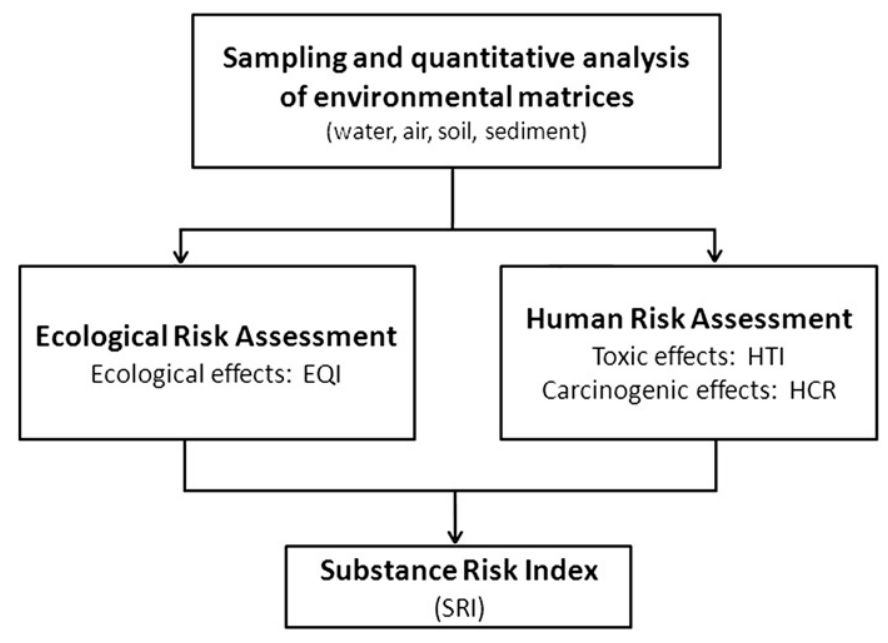

Fig. 1. Information from environmental sampling and analyses are used to evaluate the impact on human (HTI and HCR) and ecological (EQI) targets. Then the integrated results provide an overall evaluation of the risk due to the exposure to a single pollutant.

method for environmental contaminants in critical and potentially dangerous sites, for instance because of the vicinity of incinerators, landfills or industries.

The index also includes "fate" parameters like bioaccumulation indicators, persistency and degradation $(\mathrm{EFI}=$ Environmental Fate and Transport Index), calculated on the basis of intrinsic properties of the compound (volatility, mobility in soil, solubility, persistence, and bioaccumulation). The EFI is fundamental to assess future toxicity likely to be long-lasting. In this factor, used as a multiplicative parameter, the "cost" of persistence and bioaccumulation in the environment is considered as an aggravation for a possible future risk due to the presence of one or more persistent pollutants.

\section{Materials and methods}

\subsection{Database structure}

The ERICA database currently contains data on 186 chemicals including their toxicity and physico-chemical properties from referenced experimental data or reliable predictive methods. The list of potentially dangerous compounds in the database focuses on these main chemical classes: polycyclic aromatic hydrocarbons (PAHs), chlorobenzenes, nitrobenzenes, phenols, chlorophenols, halogenated aliphatic hydrocarbons, polychlorinated dibenzodioxins (PCDDs), polychlorinated dibenzofurans (PCDFs), polychlorinated biphenyls (PCBs), pesticides, hydrocarbons and inorganic compounds (i.e. metals, ozone, carbon monoxide). Other compounds will be added whenever data about their physicochemical properties and toxicological profiles will be available from international databases, peer-reviewed literature or from QSAR applications.

Using the molecular names and/or CAS (Chemical Abstract Service) numbers, the two dimensional (2D) chemical structures for each compound were checked in five online databases (HSDB TOXNET, CHEM ID Plus, ChemFinder, PubChem, Safe Nite).

14 substances that are also required in regulatory risk assessments like fluorurate classes or particulate matter (PM10, PM2.5), are mixtures of chemicals. Thus, it has not been possible to define a single structure and the properties from the literature were directly reported in the database, while for the other cases the relative structure is indicated. This fact also allowed using predictive models where experimental data were missing or unreliable.
Table 1

Information for each compound contained in the excel data file.

\begin{tabular}{|c|c|c|c|c|}
\hline Identifier & $\begin{array}{l}\text { Physico- } \\
\text { chemical } \\
\text { properties }\end{array}$ & $\begin{array}{l}\text { Distribution } \\
\text { parameters }\end{array}$ & $\begin{array}{l}\text { Ecotoxicological } \\
\text { data }\end{array}$ & $\begin{array}{l}\text { Toxicological } \\
\text { data }\end{array}$ \\
\hline $\begin{array}{l}\text { Chemical } \\
\text { ID, Name, } \\
\text { CAS number, } \\
\text { SMILES }\end{array}$ & $\begin{array}{l}\text { MW, solubility, } \\
\text { biodegradation } \\
\text { (Biowin } \\
\text { model), } \mathrm{K}_{\mathrm{oa}} \\
\mathrm{K}_{\mathrm{ow}}, \mathrm{K}_{\mathrm{aw}}, \mathrm{K}_{\mathrm{oc}} \text {, } \\
\text { vapor } \\
\text { pressure, BCF, } \\
\text { BAF }\end{array}$ & $\begin{array}{l}\text { Mackay } \\
\text { model level } \\
\text { I, Mackay } \\
\text { model level } \\
\text { III-fugacity } \\
\text { model }\end{array}$ & $\begin{array}{l}\text { Acute inhalatory } \\
\text { toxicity, acute } \\
\text { oral toxicity, } \\
\text { acute water } \\
\text { toxicity }\end{array}$ & $\begin{array}{l}\text { Class of } \\
\text { carcinogenicity, } \\
\text { ingestion } \\
\text { reference dose } \\
\text { and slope } \\
\text { factor, } \\
\text { inhalation } \\
\text { reference dose } \\
\text { and slope } \\
\text { factor. }\end{array}$ \\
\hline
\end{tabular}

A structure-data file (.sdf) containing various information related to the substances (ID, SMILES, CAS number, 2D structures, physicochemical main properties) was created for modeling purposes.

In addition, an excel data file containing the groups of information for each compound was created (Table 1).

\subsection{The minimum scenario}

19 priority substances have been selected for their toxicological profiling, frequent environmental occurrence or common presence in anthropic emissions. Recent prioritization systems from authorities (e.g. Stockholm convention on persistent organic pollutants, Toxic Chemical Release list (USEPA, 2006)) were taken into account in choosing these compounds.

They reflect a minimum, heterogeneous scenario that covers all four environmental compartments (water, soil, sediment and air) considered in ERICA, and are well spread out.

The selected pollutants (As, $\mathrm{Cd}, \mathrm{Cr}, \mathrm{Hg}, \mathrm{Ni}, \mathrm{Pb}$, benzene, PAHs as benzo(a)pyrene equivalent, PCDD/PCDFs as 2,3,7,8-TCDD equivalent, PCBs as 2,3,7,8-TCDD equivalent, $\mathrm{NO}_{2}, \mathrm{SO}_{2}, \mathrm{CO}, \mathrm{O}_{3}$, PM10, PM2.5, DDT, atrazine and hexachlorobenzene) represent the minimum scenario to be considered for each compartment and endpoint while calculating the index for a case study.

For scenarios where some experimental data are missing the hazard limits are used instead. The minimum scenario is useful to get a general idea of the status of a considered area with a comparable representation for different plants or situations.

The proposed scenario should be extended with other compounds depending on the preliminary characterization of the investigated site. To define a more detailed risk scenario it is necessary to account for possible sources of contamination, the exposed receptors (human and ecological) and the environmental levels of the added pollutants. The addiction of new pollutants could better describe the environmental analysis but requires that data about their relative physico-chemical and toxicological properties are defined. These data can be derived from peer-reviewed literature, international databases, experimental values or predicted using quantitative structure-activity relationship (QSAR) models. Whenever a pollutant is fundamental to define the environmental quality but its profile is incomplete, the inclusion can be done in a conservative way using:

- The maximum score for the lacking physico-chemicals properties (e.g., solubility, persistence, BCF, environmental distribution);

- The risk threshold in the case of undefined reference dose (PNEC, RfD or slope factor).

However, it is advisable to avoid the inclusion of a compound with an incomplete set of information to prevent boost of uncertainty. 


\subsection{Ecotoxicological and toxicological values}

We used Predicted No-Effect Concentration ecotoxicological values (PNECs), physico-chemical properties and environmental fate parameters from peer-reviewed databases like ECOTOX (USEPA, 2007), TOXNET (HSDB, 2009), INERIS (INERIS, 2009), RAIS (RAIS, 2009), Chem ID Plus (Chem ID Plus, 2009), RTECS® (CCOHS, 2009), HazDat (ATSDR, 2001) and specific reviews for some critical compounds.

If different ecotoxicological data exist for the same compound, values were selected by applying the rules in the Risk Assessment Technical Guidance (European Community, 2003), updated within the REACH legislation in 2006 (European Community, 2006). These rules are summarized here with other criteria from peer-reviewed documents:

- most sensitive species;

- typical standard tests are preferred as reported in the guidelines (e.g. OECD 305 test for bioconcentration factor (OECD, 1996);

- peer-reviewed and official papers.

The applied safety factors are: median effect or lethal concentration (EC50or LC50) divided by 1000 in case of data of acute toxicity (short-term, e.g. 4 days for fish), by 100 for sub-acute toxicity data (No Observed Effect Level, medium term, e.g. 21 days for fish) and divided by 10 for sub-acute toxicity data (Chronic=long term, e.g. 30 days for fish).

The Human Quality Index (HQ) and Cancer Risk Index (CR) are calculated using the toxic and carcinogenetic parameters for human risk assessment (e.g. Reference Dose, Slope Factor, Chronic Daily Intake) from updated, reliable guidelines such as the Risk assessment Guidance for Superfund (USEPA, 1989), Environmental and Human Italian Protection Agency (APAT, 2008) and Guidelines for Carcinogen Risk Assessment (USEPA, 2005). Toxicological values for the selected pollutants were obtained from ISS/ISPESL and IRIS databases (ISS/ ISPESL, 2009; USEPA, 2009a).

\subsection{Predictive software and modelling resources}

Freely available software was used for ERICA in case of missing or unreliable experimental data. The main QSAR programs used to predict values were EPI Suite v. 4.0, ACD v. 10, DEMETRA, CAESAR, SPARC. The latest versions of these models were used to calculate missing indicators such as solubility, LogP (logarithm of the octanolwater partition coefficient) and $K_{\mathrm{oc}}$ (soil adsorption coefficient) as listed in Table 2.

The predictive abilities of the models selected for populating the ERICA database were evaluated. For each model, particular attention was paid to the evaluation of the applicability domain, transparency and model reproducibility (Eriksson et al., 2003). For example, in case of missing data the predicted acute toxicity for rainbow trout (Oncorhynchus mykiss) was calculated with the DEMETRA free and validated models. DEMETRA models evaluate the ecotoxicity of pesticides addressing the Directive $91 / 414$ on pesticides, but they are also appropriate for other environmental pollutants (Benfenati, 2007; Benfenati et al., 2007).

We also used CAESAR QSAR models, specifically built for use under REACH legislation, in case of missing or unreliable data for the following endpoints: bioconcentration factor, mutagenicity, and carcinogenicity.

To calculate the time scale for distribution of the pollutant in the environmental compartment we used the Level III Fugacity Model EPI Suite (Level III MACKAY) (USEPA, 2010) with the environmental parameters described in Mackay et al. (1992) as default values. We selected this model for its ability to predict the partitioning of an organic compound in a representative environment (Mackay et al., 1996). The Level III model in EPI Suite assumes steady state but not equilibrium conditions and allows predictions for partitioning between air, soil, sediment and water using a combination of default parameters and various input parameters that may be defined or estimated by other programs within EPI Suite (USEPA, 2010).

\subsection{Scoring systems}

The scoring system is an important point in the structure of ERICA because it allows the management and the integration of the proposed parameters characterized by different units of measurements. In our Index, the use of an objective scoring systems is also useful to include the environmental properties (mobility, persistence, water solubility, volatility and bioaccumulation tendency) of selected compounds into a single parameter $\left(\mathrm{EF}_{\text {compound }}\right)$ used to describe the environmental fate of the pollutants.

All the adopted scoring systems for ecotoxicological, toxicological and physico-chemical parameters are reported in the Supporting Information (SI).

\subsection{Case study}

In order to validate the ERICA approach and evaluate its robustness, we applied it on a dedicated scenario based on Italian legal limits and quality objectives for environmental matrices (air, water and soil).

Furthermore a pilot case was set up on the surrounding area of a landfill sited nearby the Italian seacoast.

Table 2

Overview of the software applied and relative endpoints.

\begin{tabular}{|c|c|c|c|c|c|c|}
\hline Software & Environmental endpoints ${ }^{\mathrm{a}, \mathrm{b}, \mathrm{c}}$ & Physico chemical properties ${ }^{\mathrm{d}}$ & Fate Parameters ${ }^{\mathrm{e}}$ & Carcinogenicity $^{\mathrm{f}}$ & Skin sensitisation ${ }^{\mathrm{g}}$ & Mutagenicity $^{\mathrm{h}}$ \\
\hline DRAGON & $\mathbf{x}$ & $\mathbf{x}$ & $\mathbf{x}$ & & & \\
\hline DEMETRA & $\mathbf{x}$ & & & & & \\
\hline EPI Suite & $\mathbf{x}$ & $\mathbf{x}$ & $\mathbf{x}$ & & & \\
\hline CAESAR & & & $\mathbf{x}$ & $\mathbf{x}$ & $\mathbf{x}$ & $\mathbf{x}$ \\
\hline ACD & $\mathbf{x}$ & $\mathbf{x}$ & $\mathbf{x}$ & & & \\
\hline
\end{tabular}

a Water endpoints: Fish LC50 96 h, Fathead Minnow LC50, Daphnia EC50.

b Soil endpoints: bird Acute oral toxicity LD50 14-day exposure, rat oral LD50.

c Air endpoints: probability inhalation acute toxicity on rat, probability inhalation acute toxicity on mouse.

d $M W$, Log $\mathrm{K}_{\mathrm{OA}}$, Log $\mathrm{K}_{\mathrm{ow}}$, water solubility, melting point, boiling point, vapour pressure of organic chemicals.

e BCF, BAF, Henry's Law constant, aerobic and anaerobic biodegradabilities of organic chemicals, level III multimedia fugacity model and predicts partitioning of chemicals among air, soil, sediment and water under steady state conditions, biodegradation half-life for compounds containing only carbon and hydrogen.

${ }^{\mathrm{f}}$ Classification models, probability female/male mouse, probability female/male rat, weight of evidence carcinogenicity.

g Classification models.

h Classification models, Ames mutagenicity. 


\section{Theory and calculation}

ERICA is a tiered index for environmental risk evaluation based on a triad approach including ecotoxicological risk evaluation, human risk assessment and environmental fate and transport (see Fig. 2). These three main components are integrated into a single value using a dedicated scoring system that takes into account the different physico-chemical properties and toxicological profiles of the toxicants. The physico-chemical properties are included in the environmental fate and transport component together with the criteria to define a substance Persistent, Bioaccumulative and Toxic (PBT) derived from the last guidelines of the Environmental Chemical Agency (ECHA, 2008). The toxicological information is integrated in ecotoxicological or human risk assessment indices considering the risk threshold and quantifying the numbers and the extent of values in excess.

We will explain below how the ERICA index is obtained. Briefly, the final equations (Eq. (21)) identify the amount of threshold exceeded and the possible impact on human and ecological healthiness. For this purpose we will define an index to quantify the global exceeding values (ERIE, Eq. (19)), based on the indices for the health effect (SRI, Eq. (8)) and for environmental behavior (EFI, Eq. (13)) of each pollutant.

\subsection{Ecotoxicological risk assessment}

The component of ecotoxicological risk assessment used in ERICA includes the traditional risk procedures and the environmental distribution of the selected toxicants. Results from chemical analysis of the environmental matrices are used to calculate the Ecological Quality index (EQ) (Eq. (1)) as PEC values:

$E Q=P E C / P N E C$

where

PEC Predicted Environmental Concentration for a selected compound;

PNEC Predicted No-Effect Concentration for a selected compound.

When $E Q \geq 1$ there is a possible risk. Results from EQ are rated using a scoring system inspired by Finizio et al. (2001) [see SI for all the references to the score system].

\section{Site information}

\section{Sampling and quantitative analysis of environmental matrices (water, air, soil, sediment)}

2. Additional information

3. Environmental and Toxicogical profiling

4. Management of substances over risk threshold

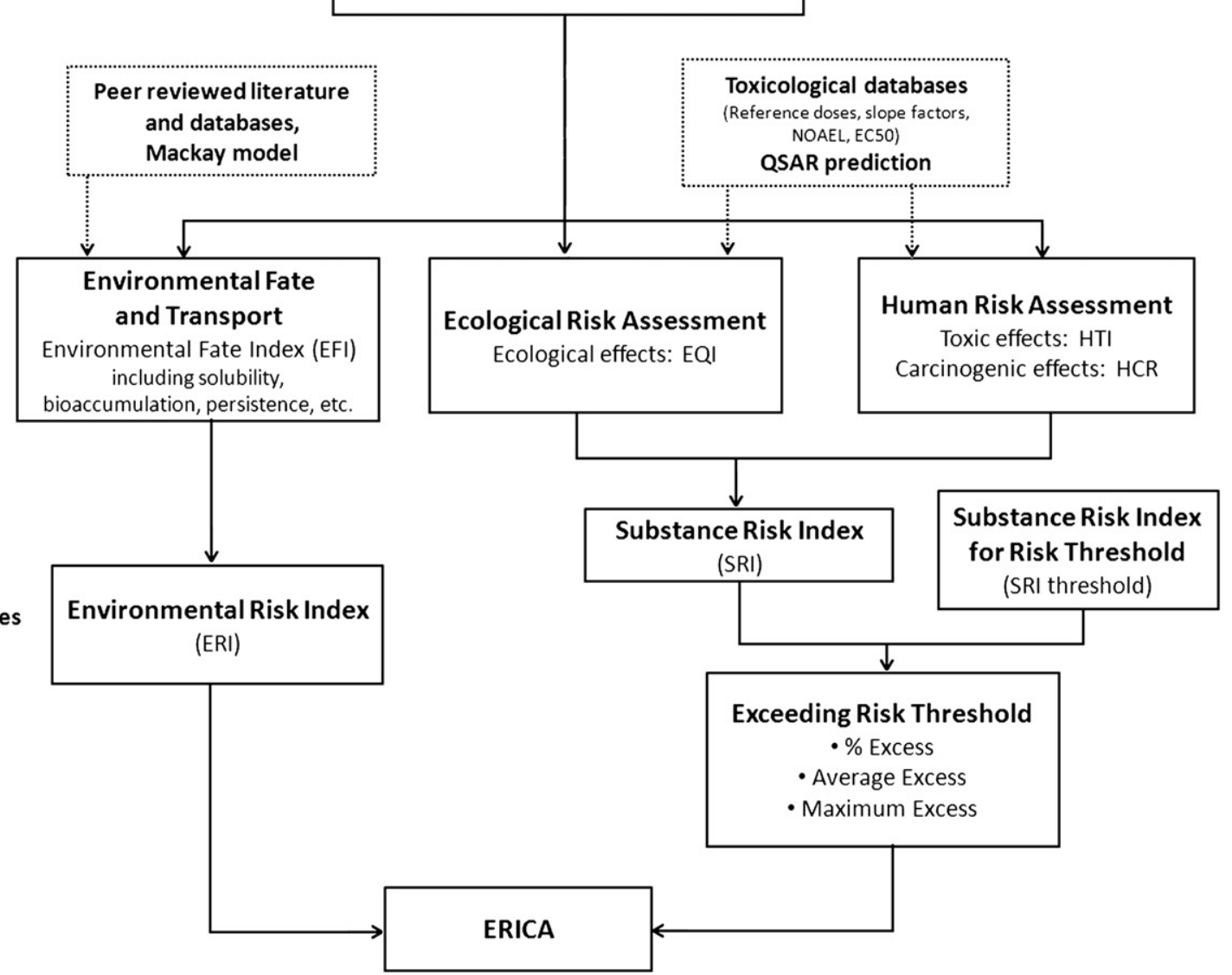

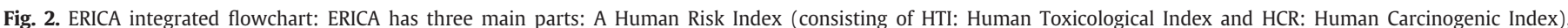

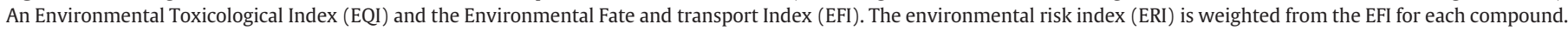

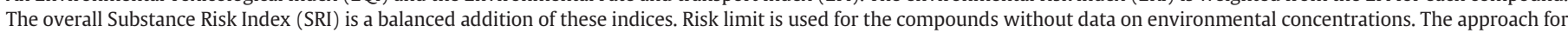
each selected pollutant is shown in the upper part while in the lowest part the integration process for the overall effects is reported. 
EQ values are calculated for each environmental matrix (air, soil, sediment and water) and translated in the relative dedicated score (see SI). The scores are integrated with the information about environmental distribution $(D)$ of the compound (see below). The Integrated index, called Ecotoxicological Quality Index (EQI) (Eq. (2)), is obtained using the following formula:

$\begin{aligned} E Q I= & \left(s E Q_{\text {soil }} \times D_{\text {soil }}\right)+\left(s E Q_{\text {water }}+\text { sediment }\right. \\ & +\left(s E Q_{\text {air }} \times D_{\text {air }}\right)\end{aligned}$

where

EQI Ecotoxicological Quality Index [unitless] [see SI];

$D_{\text {soil, }}$ water or air score for distribution of the compound into environmental compartments (calculated using Level III Fugacity Model-EPI Suite v. 4.00);

$\mathrm{sEQ}_{\text {soil, water or air }}$ score for environmental effects due to the toxicant in soil, water, sediment or air. sEQ range is 0.5-32 (see SI).

$D$ takes into account the percentage distribution of the compound derived from the fugacity model, using the following equation (Eq. (3)):

$D=1+\left[\left(9.5^{*}\right.\right.$ distribution \%) $\left./ 100\right]$

where

$D \quad$ environmental distribution of toxicant [unitless]. $D$ range is $1-10.5$;

9.5 adjustment factor to parameterize the score;

Distribution \% percentage of distribution of the toxicant in the selected matrix.

\subsection{Toxicological risk assessment for human health}

The human risk assessment comprises two modules investigating toxic (non-carcinogenic) and carcinogenic effects. Data on pollutant levels in the environmental matrices are used to calculate the Chronic Daily Intake (CDI) of toxicants due to the exposure of the human target receptors to the environmental matrix. CDI can be calculated with specific risk assessment software or using the procedures described in international guidelines [see SI].

The ERICA input parameters for the human target has been set on a residential child [see SI, Eq. A-E]. We consider this as the most conservative scenario and it gives a sensitive output for human risk assessment.

Other settings can be based on international guidelines, if the users want to apply ERICA for different scenario such as occupational assessment.

CDI is then used to calculate the Human Quality Index (HQ) and the Human Cancer Risk (CR), the two components of the human risk assessment index.

HQ (Eq. (4)) is the part of the overall index used to quantify the possible toxic effects on human receptors. It compares the calculated CDI with an estimated daily oral exposure of the human population (including sensitive subgroups) without an appreciable risk of adverse effects during a lifetime (Reference Dose, Rfd). The HQ can be calculated with the formula:

$H Q=C D I / R f D$

where

HQ estimated toxic effects of the substance [unitless];

CDI chronic daily intake $\left[\mathrm{mg}(\mathrm{kg} \mathrm{d})^{-1}\right]$;

RfD reference dose $\left[\mathrm{mg}(\mathrm{kg} \mathrm{d})^{-1}\right]$.

This relationship indicates how much the exposure from the environment exceeds the tolerable dose.
The CR (Eq. (5)), instead, describes the increase in tumor probability due to exposure to carcinogenic substances in habitual living conditions. The estimated carcinogenic effect is calculated by multiplying the CDI by the cancer risk associated with a unit dose of a carcinogen, using the following equation:

$C R=C D I \times S F$

where

CR estimated carcinogenic effect of the toxicant [unitless];

CDI Chronic Daily Intake $\left[\mathrm{mg}\left(\mathrm{kg} \mathrm{d}^{-1}\right]\right.$;

$\mathrm{SF} \quad$ slope factor $\left[\mathrm{mg}^{-1} \mathrm{~kg} \mathrm{~d}\right]$.

Results about toxic and carcinogenic effects are translated into comparable values using a dedicated scoring system [see SI, Tab. 2 and 3], then integrated, respectively, in the Human Toxicological Index (HTI) and in the Human Cancer Risk (HCR). These two parameters take into account the adverse effects on target receptors and the environmental distribution of the selected compound.

HTI (Eq. (6)) and HCR (Eq. (7)) are obtained applying these equations:

$$
\begin{aligned}
H T I= & \left(s H Q_{\text {soil }} \times D_{\text {soil }}\right)+\left(s H Q_{\text {water }}+\right.\text { sediment } \\
+ & \left(s H Q_{\text {air }} \times D_{\text {air }}\right) \\
H C R= & \left.\left(s C R_{\text {soil }} \times D_{\text {soil }}\right)+\text { sediment }\right) \\
& +\left(s C R_{\text {air }} \times D_{\text {air }}\right)
\end{aligned}
$$

where

HTI human toxicological index to estimate the toxic effects on human receptors [unitless];

HCR human cancer risk for estimating of carcinogenic effects in human populations [unitless];

$\mathrm{sHQ}_{\text {soil, water or air }}$ score for human toxic effects due to the toxicant in soil, water, sediment or air [unitless] (see SI);

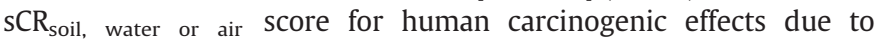
the toxicant in soil, water, sediment or air [unitless] (see SI);

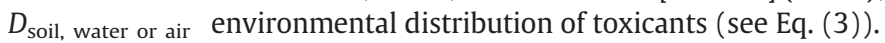

\subsection{Integration of human and ecological assessment}

Human risk assessment (HTI and HCR) and ecotoxicological risk assessment (EQI) must be done for each pollutant and the results are combined to define the Substance Risk Index (SRI), used to describe the overall effects of a compound on human populations and ecological organisms (plants and animals).

Concerning the strict relationship between human health and environmental quality, to define the SRI we assigned an equal "weight" to the effects on ecological and human targets (see Fig. 1). In this way the evaluation of pollutant impact on both kinds of receptors is balanced: a multiplying factor of 0.25 was assigned to each part of the human risk assessment (HTI and HCR) in order to equally counterbalance the weight $(0.5)$ of ecotoxicological risk assessment. So SRI is defined by the formula (Eq. (8)):

$S R I=(0.5 \times E Q I)+(0.25 \times H T I)+(0.25 \times H C R)$

The SRI is one of the components of the Environmental Risk Index (ERI) and quantifies the adverse effects on receptors also considering the environmental fate of the toxicant. 
ERI (Eq. (9)) is obtained using the formula:

$E R I=S R I \times E F I$

where

ERI environmental risk index [unitless]:

EFI environmental fate index [unitless], describing the environmental fate and transport of the toxicants.

The EFI indicates the potential danger of exposure on a time scale. It is based on the fate and environmental properties (mobility, persistence, water solubility, volatility and bioaccumulation tendency). This measure shows if the levels of a compound could rise over time, becoming a matter of concern for the future.

The EFI relationship (Eq. (10)) has the following equation:

$E F I=1+\left[\left(E F_{\text {compound }}-E F_{\text {min }}\right) / E F_{\max }\right]$

where

$\mathrm{EF}_{\text {compound }}$ environmental fate of the compound [unitless] (Eq. (11)) (see below and the SI);

$\mathrm{EF}_{\text {min }}$ minimum $\mathrm{EF}$ value for an ideal compound (=2.67); (see the SI);

$\mathrm{EF}_{\max }$ maximum $\mathrm{EF}$ value for an ideal compound $(=25)$ (see $\mathrm{SI}$ );

The Environmental Fate of the toxicant $\left(\mathrm{EF}_{\text {compound }}\right)$ is related to the physico-chemical properties of the pollutants (Eq. (11)). It quantifies the most important properties influencing the behavior of the xenobiotic in the environmental matrix. The formula to calculate EF compound is the following:

$E F_{\text {compound }}=(S+M) / V+B C F+P$

where

S score for the water solubility of the compound [see SI, Tab. 4]; M score for the mobility of the compound, based on Koc value [see SI, Tab. 5];

$V \quad$ score for the volatility of the pollutants, based on its vapor pressure [see SI, Tab. 6];

BCF score for the bioconcentration property, expressed as the logarithm of compound's BCF or BAF [see SI, Tab. 7];

$P \quad$ score for the persistence of the pollutant, described as degradation time [see SI, Tab. 8].

Other physico-chemical properties might be added to the definition of the EF subindex following future developments and data availability. For example, data on photolysis could be useful to describe the stability of a pollutant when it is released into an environmental matrix.

\subsection{ERICA for macropollutants}

A large number of studies have been done on the toxicity of macropollutants such as ozone, particulate matter (PM10 and PM2.5), carbon monoxide, nitrogen dioxide and sulfur dioxide (Council Directive 96/62/EC). In 1999, USEPA released the Air Quality Index (AQI), a simplified method to evaluate the probability of adverse effects in human and environmental target exposed to this group of substances (USEPA, 1999a). The AQI is a daily index for reporting air quality and focuses on health and environmental effects due to exposure to polluted air. USEPA calculates the AQI for the six major air pollutants regulated by the Clean Air Act. Under this act, USEPA has established the National Ambient Air Quality Standards (NAAQS) that can be used as reference doses to protect public health (Primary Standards) and the environment (Secondary Standard) (USEPA, 1999b). These values are periodically revised on the basis of epidemiological studies.

We created the specific approach for macropollutants based on the $\mathrm{AQI}$ approach because it is scientifically based but easily understandable. We used different methods to calculate AQI for the assessment of human health (Eq. (12)) and for the environment (Eq. (13)).

The AQI equation for human targets is

$A Q I=\left[\left(I_{\mathrm{Hi}}-I_{\mathrm{Lo}}\right) /\left(B P C_{\mathrm{Hi}}-B P C_{\mathrm{Lo}}\right)\right] \times\left(C-B P C_{\mathrm{Lo}}\right)+I_{\mathrm{Lo}}$

where

AQI Air Quality Index for the selected pollutant [unitless];

$I_{\mathrm{Hi}} \quad \mathrm{AQI}$ values corresponding to $\mathrm{BPC}_{\mathrm{Hi}}$ [unitless];

$I_{\mathrm{Lo}} \quad \mathrm{AQI}$ values corresponding to $\mathrm{BPC}_{\mathrm{Lo}}$ [unitless];

$\mathrm{BPC}_{\mathrm{Hi}}$ breaking point concentration equal or greater than $\mathrm{C}$ for the selected pollutant $\left[\mathrm{mg} \mathrm{m}^{-3}\right]$;

$\mathrm{BPC}_{\mathrm{Lo}} \quad$ breaking point concentration less than $C$ for the selected compound $\left[\mathrm{mg} \mathrm{m}^{-3}\right]$;

C concentration of the selected pollutant $\left[\mathrm{mg} \mathrm{m}^{-3}\right]$.

Breaking point concentrations are based on NAAQS and are reported in AQI technical guidance (USEPA, 2009b).

For environmental risk assessment the AQI formula is:

$A Q I=(100 \times C) / N A A Q S$

where

AQI Air Quality Index for the selected pollutant [unitless];

$C \quad$ concentration of the selected pollutant $\left[\mathrm{mg} \mathrm{m}^{-3}\right]$;

NAAQS secondary standard from NAAQS for investigated compound $\left[\mathrm{mg} \mathrm{m}^{-3}\right]$.

An AQI value of 100 corresponds to the NAAQS for the pollutant, which is the safety level set by USEPA to protect public health and the environment. AQI values below 100 are satisfactory but when they are above 100 the air quality is considered unhealthy, first for certain sensitive groups of people, then for everyone.

AQI is fully referenced and transparent and it was added to ERICA for macroinorganic toxicants [see SI, Tab. 9] using a dedicated scoring system. $\mathrm{AQI}$ values are directly integrated into ERI using the following equation:

$E R I=\left(0.5 \times s A Q I_{\text {eсо }}\right)+\left(0.5 \times s A Q I_{\text {hum }}\right)$

where

ERI Substance Risk Index for a selected macropollutant [unitless];

$\mathrm{SAQI}_{\text {eco }}$ score corresponding to the AQI data for the ecological target;

$S A Q I_{\text {hum }}$ score referred to the AQI value for human health.

\subsection{Managing toxicants exceeding the risk threshold}

An increased probability of adverse effect on human and environmental targets is linked to the exceeding of the risk threshold by a substance.

For each priority pollutant, the SRI is compared with a risk threshold to verify if pollutant's effect exceeds the safety level. The Pollutant Risk Index, PI (Eq. (15)) is described by the equation:

$P I=S R I_{\text {toxicant }} / S R I_{\text {threshold }}$

The number of toxicants with pollutant risk $>1$ must be noted down as the number of pollutants exceeding risk threshold (NEP) and 
it will be successively used to calculate the percentage of toxicants that exceed risk threshold (Eq. (17)). For each exceeding value, the Exceeding Risk (ER) (Eq. (16)) is calculated as follow:

Exceeding Risk $=$ Pollutant Risk -1

We decided to enhance the possible hazard due to exceeding of risk threshold introducing a set of additional parameters for pollutants that exceed the risk threshold (as previously described by Eqs. (15) and (16)).

We may have cases where there are many of toxicants exceeding the risk threshold or cases where there is a single pollutant with a high value. These two situations have to be considered separately as below indicated.

First of all, the number of these compounds (Number of Exceeding Pollutant, NEP) is used to obtain their percentage by the formula:

$\% E=(N E P / N I C) \times 100$

where

$\% E$ percentage of toxicants that exceed the risk threshold [\%] range $0-1$;

NEP number of pollutants exceeding the risk threshold [unitless];

NIC number of investigated priority compounds [unitless].

Then, the average and the maximum of ER, average exceeding $(\mathrm{AE})$, and the maximum exceeding (ME), are calculated. These last two factors are used to obtain the Integrated Threshold Exceeding (ITE) using the formula:

$I T E=1+(A E \times M E)$

\subsection{Final integrations}

The ERI must be calculated for each priority pollutant and the results are analyzed to obtain the average ERI for the investigated scenario (Eq. (19)):

$<E R I>=\left(E R I_{1}+E R I_{2}+E R I_{3}+\ldots+E R I_{x}\right) / x$

ERI is an important parameter to describe the global situation of an investigated area and it is integrated with the previously defined number of pollutants exceeding the risk threshold. The integrated parameter is called the Environmental Risk Index and Exceeding value (ERIE) and takes into account the percentage of toxicants above the risk threshold and the average ERI values for the investigated scenario.

ERIE is obtained as follows:

$E R I E=(1+\% E) \times<E R I>$

where

ERIE Environmental Risk Index and Exceeding value [unitless]; $\%$ percentage of toxicants that exceed risk threshold (see Eq. (17)).

Finally, ERICA can be calculated (Fig. 2). This final index integrates data from human and ecotoxicological risk assessment, physicochemical-based environmental fate and data on risk threshold excesses. The equation used to derive ERICA is:

$E R I C A=\left[(E R I E \times 100) / E^{2} I E_{\text {risk threshold }}\right] \times I T E$

where

ERICA environmental risk index for chemical assessment [unitless]; ERIE $_{\text {risk threshold }}$ ERIE value corresponding to risk threshold [unitless]; ITE Integrate Threshold Exceeding (see Eq. (18)).
The ERICA final value is used to define the Environmental Quality by a tiered classification similar to the "Air Quality Index" (USEPA, 1999a). It is divided into eight categories from "very good" to "hazardous". Each category corresponds to a different level of environmental health concern.

The eight levels (see Fig. 3) are:

- "Very good": ERICA is $0-<25$, the environmental health quality is satisfactory and pollution poses no risk for human and ecological receptors;

- "Good": ERICA is 25-49, the environmental health quality is satisfactory and pollution causes little risk;

- "Moderate": ERICA is 50-99 the environmental health quality is acceptable but there may be a moderate health concern for some pollutants;

- "Unhealthy for sensitive groups": ERICA is 100-149, human and ecological targets are not affected by risk but the most sensitive receptors (e.g. people with heart and lung disease, children and older adults) start to be affected by risk;

- "Unhealthy": ERICA is 150-199, every target may begin to experience some adverse effects and most sensitive ones may be subject to risk;

- "Very Unhealthy": ERICA is 200-299; this category could trigger health or environmental alert because all receptors could be affected by risks:

- "Dangerous": ERICA is 300-399, and targets are in danger with substantial risks;

- "Hazardous": ERICA is $>400$, corresponding to emergency conditions because all the receptors are affected by serious adverse risks.

Following the USEPA approach, we selected a color for each ERICA category to make the results easy to understand to the audience.

\section{Results}

To validate ERICA and evaluate its robustness we applied it on a dedicated scenario based on Italian legal limits and quality objectives for environmental matrices. Moreover, this paper presents a case study concerning an Italian seacoast site where a landfill is present.

In case of missing input data (no set limits for some pollutant) we set SRI equal to the risk threshold $(=1)$, as previously described.

Sub-indexes and final ERICA values for both case studies are reported in Table 3.

ERICA gives a score of 147.4 for the Italian limit scenario, corresponding to an "unhealthy for sensitive groups" classification while for the pilot case, where data on pollutants' environmental levels are available, ERICA gives a score of 116 corresponding to an "Unhealthy for sensitive groups" scenario (Fig. 4).

\begin{tabular}{|c|c|}
\hline Environmental Quality & ERICA \\
\hline Very Good & $<25$ \\
\hline Good & $25-49$ \\
\hline Moderate & $50-99$ \\
\hline Unhealthy for sensitive groups & $100-149$ \\
\hline Unhealthy & $150-199$ \\
\hline Very Unhealthy & $200-299$ \\
\hline Dangerous & $300-399$ \\
\hline Extremely Dangerous & $\geq 400$ \\
\hline
\end{tabular}

Fig. 3. The eight levels of concern describing the health status of a territory with ERICA. 
Table 3

Sub-indexes and final ERICA values for the pilot case and for the law limit case. In case of missing input data we set SRI equal to the risk threshold $(=1)$, as previously described.

\begin{tabular}{|c|c|c|c|c|c|c|c|c|c|c|c|c|c|c|c|c|c|c|c|c|c|c|c|c|c|}
\hline \multirow[t]{2}{*}{ Case study } & \multirow[t]{2}{*}{ Pollutants } & \multicolumn{4}{|l|}{ Soil } & \multicolumn{4}{|c|}{ Water } & \multicolumn{4}{|l|}{ Air } & \multirow[t]{2}{*}{ EQI } & \multirow[t]{2}{*}{$\mathrm{HQI}$} & \multirow[t]{2}{*}{ HCR } & \multirow[t]{2}{*}{ SRI } & \multirow[t]{2}{*}{ SRi limit } & \multirow[t]{2}{*}{ PI } & \multirow[t]{2}{*}{ EF } & \multirow[t]{2}{*}{ EFI } & \multirow[t]{2}{*}{ ERI } & \multirow[t]{2}{*}{$<$ ERI $>$} & \multirow[t]{2}{*}{ ERIE } & ERICA \\
\hline & & sEQ & sHQ & $\mathrm{sHC}$ & D & sEQ & sHQ & $\mathrm{sHC}$ & D & $\mathrm{sEQ}$ & sHQ & $\mathrm{sHC}$ & D & & & & & & & & & & & & \\
\hline Law Limit Case & Arsenic & 16 & 32 & 32 & 4.17 & 4 & 4 & 32 & 4.17 & 0.5 & 1 & 16 & 4.17 & 85.42 & 154.17 & 333.33 & 164.58 & 100.00 & 1.65 & 19.00 & 1.65 & 272.09 & & & \\
\hline & Cadmium & 16 & 32 & 0 & 4.17 & 16 & 4 & 0 & 4.17 & 0.5 & 2 & 4 & 4.17 & 135.42 & 158.33 & 16.67 & 111.46 & 83.33 & 1.34 & 19.00 & 1.65 & 184.26 & & & \\
\hline & Chromium & 2 & 32 & 0 & 4.17 & 0.5 & 1 & 0 & 4.17 & 8 & 8 & 0 & 4.17 & 43.75 & 170.83 & 0.00 & 64.58 & 75.00 & 0.86 & 13.00 & 1.41 & 91.27 & & & \\
\hline & Mercury & 2 & 32 & 0 & 4.17 & 16 & 4 & 0 & 4.17 & 8 & 8 & 0 & 4.17 & 108.33 & 183.33 & 0.00 & 100.00 & 75.00 & 1.33 & 15.00 & 1.49 & 149.32 & & & \\
\hline & Nichel & 16 & 32 & 0 & 4.17 & 4 & 2 & 0 & 4.17 & 0.5 & 0.5 & 4 & 4.17 & 85.42 & 143.75 & 16.67 & 82.81 & 83.33 & 0.99 & 19.00 & 1.65 & 136.91 & & & \\
\hline & Lead & 16 & 32 & 0 & 4.17 & 16 & 4 & 0 & 4.17 & 0.5 & 2 & 0 & 4.17 & 135.42 & 158.33 & 0.00 & 107.29 & 75.00 & 1.43 & 15.00 & 1.49 & 160.21 & & & \\
\hline & Benzene & 1 & 16 & 32 & 3.54 & 2 & 1 & 2 & 4.94 & 0.5 & 2 & 16 & 4.02 & 15.43 & 69.57 & 187.35 & 71.95 & 99.98 & 0.72 & 9.33 & 1.27 & 91.13 & & & \\
\hline & PAHs & 0.5 & 0.5 & 2 & 4.59 & 16 & 8 & 2 & 6.91 & 0.5 & 0.5 & 2 & 1.00 & 113.30 & 58.05 & 25.00 & 77.41 & 100.01 & 0.77 & 12.00 & 1.37 & 106.30 & & & \\
\hline & Dioxins & 4 & 4 & 32 & 7.37 & 4 & 0.5 & 4 & 4.12 & 8 & 8 & 8 & 1.01 & 54.02 & 39.60 & 260.24 & 101.97 & 99.96 & 1.02 & 14.00 & 1.45 & 148.18 & & & \\
\hline & PCBs & 8 & 8 & 32 & 7.37 & 4 & 8 & 8 & 4.12 & 8 & 8 & 8 & 1.01 & 83.48 & 99.96 & 276.72 & 135.91 & 99.96 & 1.36 & 14.00 & 1.45 & 197.50 & 146.70 & 223.92 & 147.40 \\
\hline & $\mathrm{HCB}$ & 1 & 32 & 32 & 9.90 & 0.5 & 0.5 & 2 & 1.46 & 8 & 8 & 8 & 1.14 & 19.76 & 326.70 & 328.89 & 173.78 & 100.02 & 1.74 & 13.00 & 1.41 & 245.58 & & & \\
\hline & DDT & 4 & 16 & 32 & 6.70 & 32 & 1 & 2 & 4.77 & 8 & 8 & 8 & 1.02 & 187.73 & 120.15 & 232.13 & 181.93 & 99.97 & 1.82 & 12.00 & 1.37 & 249.83 & & & \\
\hline & Atrazine & 4 & 2 & 32 & 9.28 & 32 & 0.5 & 2 & 2.21 & 8 & 8 & 8 & 1.00 & 115.98 & 27.68 & 309.52 & 142.29 & 99.99 & 1.42 & 14.00 & 1.45 & 206.78 & & & \\
\hline & NOx & & & & & & & & & 12 & 12 & & & & & & 12.0 & 139 & 0.1 & & & 12.00 & & & \\
\hline & SOx & & & & & & & & & 12 & 70 & & & & & & 41.0 & 139 & 0.3 & & & 41.00 & & & \\
\hline & $\mathrm{CO}$ & & & & & & & & & 605 & 70 & & & & & & 337.5 & 139 & 2.4 & & & 337.50 & & & \\
\hline & 03 & & & & & & & & & 70 & 70 & & & & & & 70.0 & 139 & 0.5 & & & 70.00 & & & \\
\hline & PM10 & & & & & & & & & 12 & 12 & & & & & & 12.0 & 139 & 0.1 & & & 12.00 & & & \\
\hline & PM2.5 & & & & & & & & & 139 & 12 & & & & & & 75.5 & 139 & 0.5 & & & 75.50 & & & \\
\hline Case Study & Arsenic & 4 & 32 & 32 & 4.17 & 8 & 8 & 8 & 4.17 & 0.5 & 0.5 & 2 & 4.17 & 52.1 & 168.8 & 175.0 & 112.0 & 100.0 & 1.1 & 19.0 & 1.65 & 185.12 & & & \\
\hline & Cadmium & 16 & 32 & 0 & 4.17 & 8 & 8 & 0 & 4.17 & 0.5 & 1 & 4 & 4.17 & 102.1 & 170.8 & 16.7 & 97.9 & 83.3 & 1.2 & 19.0 & 1.65 & 161.88 & & & \\
\hline & Chromium & 4 & 16 & 0 & 4.17 & 8 & 8 & 0 & 4.17 & 1 & 0.5 & 0 & 4.17 & 54.2 & 102.1 & 0.0 & 52.6 & 75.0 & 0.7 & 13.0 & 1.41 & 74.34 & & & \\
\hline & Mercury & 2 & 32 & 0 & 4.17 & 8 & 8 & 0 & 4.17 & 0.5 & 1 & 0 & 4.17 & 43.8 & 170.8 & 0.0 & 64.6 & 75.0 & 0.9 & 15.0 & 1.49 & 96.44 & & & \\
\hline & Nichel & 4 & 32 & 0 & 4.17 & 8 & 8 & 0 & 4.17 & 0.5 & 0.5 & 4 & 4.17 & 52.1 & 168.8 & 16.7 & 72.4 & 83.3 & 0.9 & 19.0 & 1.65 & 119.68 & & & \\
\hline & Lead & 16 & 32 & 0 & 4.17 & 8 & 8 & 0 & 4.17 & 0.5 & 1 & 0 & 4.17 & 102.1 & 170.8 & 0.0 & 93.8 & 75.0 & 1.3 & 15.0 & 1.49 & 139.99 & & & \\
\hline & Benzene & 8 & 8 & 8 & 3.54 & 8 & 8 & 8 & 4.94 & 0.5 & 0.5 & 1 & 4.02 & 69.8 & 69.8 & 71.8 & 70.3 & 100.0 & 0.7 & 9.3 & 1.27 & 89.07 & & & \\
\hline & PAHs & 0.5 & 0.5 & 32 & 4.59 & 8 & 8 & 8 & 6.91 & 0.5 & 0.5 & 2 & 1.00 & 58.0 & 58.0 & 204.2 & 94.6 & 100.0 & 0.9 & 12.0 & 1.37 & 129.87 & & & \\
\hline & Dioxins & 4 & 2 & 32 & 7.37 & 8 & 8 & 8 & 412 & 05 & 1 & 2 & 1.01 & 62.9 & 48.7 & 270.7 & 111.3 & 100.0 & 1.1 & 14.0 & 1.45 & 161.74 & & & \\
\hline & PCBs & 4 & 2 & 32 & 7.37 & 8 & 8 & 8 & 4.12 & 0.5 & 1 & 2 & 1.01 & 62.9 & 48.7 & 270.7 & 111.3 & 100.0 & 1.1 & 14.0 & 1.45 & 161.74 & 122.73 & 187.32 & 116.00 \\
\hline & $\mathrm{HCB}$ & 8 & 8 & 8 & 9.90 & 8 & 8 & 8 & 1.46 & 8 & 8 & 8 & 1.14 & 100.0 & 100.0 & 100.0 & 100.0 & 100.0 & 1.0 & 13.0 & 1.41 & 141.34 & & & \\
\hline & DDT & 8 & 8 & 8 & 6.70 & 8 & 8 & 8 & 4.77 & 8 & 8 & 8 & 1.02 & 100.0 & 100.0 & 100.0 & 100.0 & 100.0 & 1.0 & 12.0 & 1.37 & 137.27 & & & \\
\hline & Atrazine & 8 & 8 & 8 & 9.28 & 8 & 8 & 8 & 2.21 & 8 & 8 & 8 & 1.00 & 100.0 & 100.0 & 100.0 & 100.0 & 100.0 & 1.0 & 14.0 & 1.45 & 145.31 & & & \\
\hline & NOx & & & & & & & & & 12 & 12 & & & & & & 12.0 & 139.0 & 0.1 & & & 12.0 & & & \\
\hline & SOx & & & & & & & & & 12 & 12 & & & & & & 12.0 & 139.0 & 0.1 & & & 12.0 & & & \\
\hline & $\mathrm{CO}$ & & & & & & & & & 139 & 139 & & & & & & 139.0 & 139.0 & 1.0 & & & 139.0 & & & \\
\hline & 03 & & & & & & & & & 12 & 12 & & & & & & 12.0 & 139.0 & 0.1 & & & 12.0 & & & \\
\hline & PM10 & & & & & & & & & 12 & 70 & & & & & & 41.0 & 139.0 & 0.3 & & & 41.0 & & & \\
\hline & PM2.5 & & & & & & & & & 605 & 139 & & & & & & 372.0 & 139.0 & 2.7 & & & 372.0 & & & \\
\hline
\end{tabular}




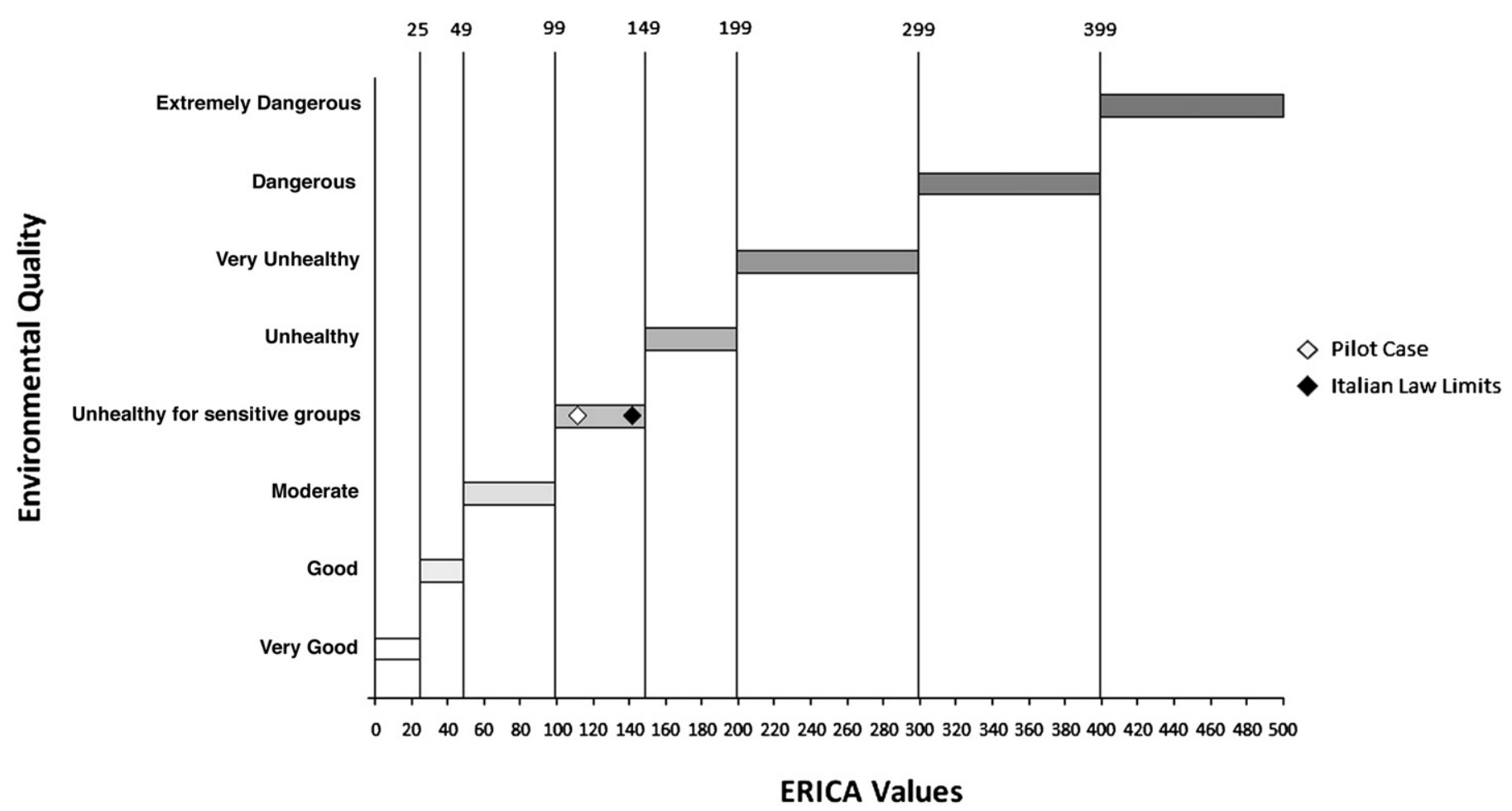

Fig. 4. Pilot case and law limit case values in ERICA classification diagram.

\section{Discussion}

In the Italian legislation, there are no defined limits for few pollutants in some environmental compartments. Furthermore the legal limits derive from many considerations such as toxicology, politics and recent advances in technology and, in some cases, do not reflect the application of health and ecological risk limits. Instead, the overall ERICA depicts a health scenario focused on the health risk limit for all the environmental compartments.

The high ERICA value using the Italian legal limit reflects the threshold value for risk for the environmental status considered in its completeness. As we said previously, we used the risk limit where the legal limits are missing (PCBs in water, PAHs in water and chromium, mercury, dioxins, PCBs, HCB, DDT and atrazine in air).

The pilot case is related to an area surrounding a landfill in a coastal site in Italy. A detailed risk evaluation analysis was conducted in our laboratories to define the environmental and toxic risks related to the landfill emissions. The compounds exceeding the Italian law limit were: PM10, Ni, Cd, Sn in air and soil samples monitored during 3 months in different areas. The detailed risk analysis showed possible risks for sensitive groups related to the dermal contact within the soil. Furthermore the values of PM2.5, Sb, Cd, Pb and V show a possible risk for sensitive groups and environment.

ERICA condensed value defines in a unique number the possible risks for sensitive groups and the single values of SRI of each compounds well identify the risks reported in Table 3.

\section{Conclusions}

A risk assessment strategy considering the impact of chemicals on the whole ecosystem has been developed, taking into consideration the physico-chemical, toxicological and ecotoxicological properties related to various species and environmental compartments.

The condensed information provided by ERICA makes it easy to classify the health of a territory even following time variations. Our approach is general and flexible. Additional information like new alternative chemicals of interest (such as pharmaceuticals) and new toxicological characteristics may be added, on condition that added information is complete and available also for the compounds of the minimum scenario. Furthermore, the model can be easily extended with additional information from different assays (ecotoxicological, endocrine disruptors or in vitro tests) or from epidemiological and socio-economic studies.

ERICA considers the site-specific chemical loads and can be further analyzed to define a single chemical change and the inherent toxicity or to group the overall chemical impact and potential effect in a given area.

ERICA is intended as a tool for those deciding on environmental policy because it is concise and transparent:

1) It takes into account how far the healthiness of the investigated site is from the risk threshold, so it is not only an acceptable or notbinary classification;

2) It takes into account the overall mixture of pollutants assessing their toxicological and ecotoxicological weights and giving a picture of their impact;

3) It can manage cases with little data, thanks to predictive methods;

4) It allows an impartial judgment on the health of a territory, communicating in a straightforward manner;

5) It allows an overall evaluation of the time trend of environmental impact on a studied location;

6) It can be used to compare spatial situations (in different scales) which otherwise can be compared with difficulties;

7) ERICA can be a useful tool for the estimation of "toxicity flux" relayed to the international transport of material, such as waste.

Moreover, ERICA could be a valid answer to the recently described need of analytic tools for integrated health impact assessment (Bhatia and Wernham, 2008).

\section{Acknowledgments}

We gratefully acknowledge MIUR project FIRB number RBIP/ 06993E_00 and RISKCYCLE EU project (FP7-COOPERATION contract number 226552). 
We would like to thank Dr. Mauro Tettamanti from the Epidemiology Unit at Mario Negri Institute for his help with mathematical elaborations and Dr. Vincenzo Senese from Industrial and Environmental Health Unit at Mario Negri Institute for training with MacKay model.

\section{Appendix A. Supplementary data}

Supplementary data associated with this article can be found, in the online version, at doi:10.1016/j.envint.2010.04.019.

\section{References}

ACD, v. 10 Available from http://www.acdlabs.com/.

Agency for Toxic Substances and Diseases Registry (ATSDR), 2001. HazDat Database. Available at http://www.emla.hu/prtr/chems/hazdat.html.

Agenzia per la Protezione dell'Ambiente e per i servizi Tecnici (APAT), 2008. Criteri metodologici per l'applicazione dell'analisi assoluta di rischio ai siti contaminati. Available at http://www.apat.gov.it/site/en-GB/Topics/Contaminated_sites/Risk_analysis/default. html.

Benfenati E. Predicting toxicity through computers: a changing world. Chem Cent J $2007 ; 1: 32$.

Benfenati E, Chrétien JR, Gini G, Piclin N, Pintore M, Roncaglioni A. Validation of the models. In: Benfenati E, editor. Quantitative Structure-Activity Relationships (QSAR) for pesticide regulatory purposes. Amsterdam, The Netherlands: Elsevier Science Ltd; 2007. p. 185-99.

Bhatia R, Wernham A. Integrating human health into environmental impact assessment: an unrealized opportunity for environmental health and justice. Environ Health Perspect 2008;116:991-1000.

CAESAR EC project. Available at http://www.caesar-project.eu.

Canadian Centre for Occupational Health and Safety (CCOHS), 2009. Registry of toxic effects of chemical substances. Available at http://ccinfoweb.ccohs.ca/.

Chem ID Plus, 2009. Available at http://chem.sis.nlm.nih.gov/chemidplus/.

ChemFinder, 2009. Available at http://chemfinder.cambridgesoft.com.

Council Directive 96/62/EC of 27 September 1996 on ambient air quality assessment and management.

DEMETRA EC project. Available at http://www.demetra-tox.net.

Department for Environment Food and Rural affairs (DEFRA). Report of indicators reflecting the impacts of pesticide use, pesticide forum. London: Department of Environment, Food and Rural Affairs; 2006.

Eriksson L, Jaworska J, Worth A, Cronin M, McDowell RM, Gramatica P. Methods for reliability, uncertainty assessment, and applicability evaluations of regression based and classification QSARs. Environ. Health Perspect 2003;111:1361-75.

European Chemical Agency (ECHA), 2008. Guidance on information requirements and chemical safety assessment - Chapter R.11: PBT Assessment. Available at http:// guidance.echa.europa.eu/docs/guidance_document/information_requirements_en. htm?time $=1253002361 \#$ r11.

European Community, 2003. Technical Guidance Document on Risk Assessment in support of Commission Directive 93/67/EEC on risk assessment for New Notified Substances and Commission Regulation (EC) No. 1488/94 on Risk Assessment for Existing Substances and Directive 98/8/EC of the European Parliament and of the Council concerning the placing of biocidal products on the market.

European Community, 2006. Regulation (EC) No 1907/2006 of the European Parliament and of the Council of 18 December 2006 concerning the Registration, Evaluation, Authorisation and Restriction of Chemicals (REACH), establishing a European Chemicals Agency, amending Directive 1999/45/EC and repealing Council Regulation (EEC) No 793/93 and Commission Regulation (EC) No 1488/94 as well as Council Directive 76/769/EEC and Commission Directives 91/155/EEC, 93/67/EEC, 93/105/EC and 2000/21/EC. OJ L 396, 30.12.2006, p. 1-849. Available at http://ec.europa.eu/enterprise/sectors/chemicals/documents/reach/ index_en.htm.

EUSES, 2008. EUSES, the European Union System for the Evaluation of Substances, version 2.1. National Institute of Public Health and the Environment (RIVM), the Netherlands. Available via the European Chemicals Bureau at http://ecb.jrc.it.

Finizio A, Calliera M, Vighi M. Rating systems for pesticide risk classification on different ecosystems. Ecotoxicol Environ Saf 2001;49:262-74.
Hazardous Substances Data Bank [Internet], 2009 HSDB TOXNET, Bethesda (MD): National Library of Medicine (US); [Last Revision Date 2009] Available at: http:// toxnet.nlm.nih.gov/cgi-bin/sis/htmlgen?HSDB.

Huijbregts MAJ, Thissen U, Guine JB, Jager T, Kalfe D, van de Meent D, et al. Priority assessment of toxic substances in life cycle assessment. Part I: calculation of toxicity potentials for 181 substances with the nested multi-media fate, exposure and effects model USES \pm LCA. Chemosphere 2000;41:541-73.

INERIS, 2009. Institut National de l'Environnement industriel et des risques, 2009 INERIS Environmental database. Available at http://chimie.ineris.fr/en/.

ISS/ISPESL, 2009. ISPRA/ISPESL database "Chemical/physical and toxicological properties of pollutants". Available at http://www.apat.gov.it/site/_files/Suolo_Territorio/ Banca_dati_ISS_ISPESL_Maggio_2009.xls.

Mackay D, Paterson S, Shiu WY. Generic models for evaluating the regional fate of chemicals. Chemosphere 1992;24:695-718.

Mackay D, Di Guardo A, Paterson S, Kicsi G, Cowan CE. Assessing the fate of new and existing chemicals: a five-stage process. Environ Toxicol Chem 1996;15:1618-26.

OECD, 2009. Chemical Testing Guidelines. Available at http://www.oecd.org/ department/0,3355,en_2649_34377_1_1_1_1_1,00.html.

Organisation for Economic Co-operation and Development (OECD). Test No. 305: Bioconcentration: flow-through fish test. OECD guidelines for the testing of chemicals / Section 3: degradation and accumulation; 1996.

PubChem Compound. Available at http://www.ncbi.nlm.nih.gov/sites/.

Risk Assessment Information System (RAIS), 2009. Available at http://rais.ornl.gov/.

RIVM (The National Institute for Public Health and the Environment), 2003. Report 601200001/2003: Inventory of revisions in the EC Technical Guidance. Documents (TGDs) on risk assessment of chemicals. Available at http://ecb.jrc.ec. europa.eu/documents/TECHNICAL_GUIDANCE_DOCUMENT/EDITION_2/RIVM_report_60120001_final.pdf.

Rosenbaum RK, Bachmann TM, Swirsky Gold L, Huijbregts MAJ, Jolliet O, Juraske R, et al. USEtox-the UNEP-SETAC toxicity model: recommended characterisation factors for human toxicity and freshwater ecotoxicity in life cycle impact assessment. Int Life Cycle Assess 2008;13:532-46.

Safe Nite Japan. Available at http://www.safe.nite.go.jp/english/kizon/KIZON_start_hazkizon. html.

Senese V, Boriani E, Baderna D, Mariani Alessandro, Lodi M, Finizio A, Testa S, Benfenati E, 2010. Assessing the environmental risks associated with contaminated sites: definition of an ecotoxicological classification index for landfill areas (ECRIS). Chemosphere 80 (1), 60-66.

Snyder EM, Snyder SA, Giesy JP, Blonde AA, Hurlburt GK, Summer CL, et al. SCRAM: a scoring and ranking system for persistent, bioaccumulative, and toxic substances for the North American Great Lakes (Part I, II, III, IV). Environ Sci Pollut Res Int 2000;7(4):220-4.

SPARC September 2009 release w4.5.1522-s4.5.1522. Available at http://sparc.chem. uga.edu/sparc/.

United State Environmental Protection Agency (USEPA). Risk assessment guidance for superfund. Volume I: Human Health Evaluation Manual (Part A) EPA/540/1-89/002Washington, DC, 20450: Office of Emergency and Remedial Response; 1989.

USEPA. Exposure factors handbook. National Center for Environmental Assessment Office of Research and Development; 1997.

USEPA. Air quality index reporting; final rule. Fed Reg 1999a;64:149.

USEPA, 1999b. National Ambient Air Quality Standards (NAAQS). Available at http:// www.epa.gov/ttn/naaqs/.

USEPA, 2004. The Clean Air Act as Amended Through P.L. 108-20. Available at http:// epw.senate.gov/envlaws/cleanair.pdf.

USEPA. Guidelines for carcinogen risk assessment. . EPA/630/P-03/001FWashington, DC, 20450: Office of Emergency and Remedial Response; 2005.

USEPA, 2006. Toxics Release Inventory Program. Available at: http://www.epa.gov/TRI/ trichemicals/chemical\%20lists/RY2006ChemicalList.pdf.

USEPA, 2007. ECOTOX User Guide: ECOTOXicology Database System. Version 4.0. Available: http://www.epa.gov/ecotox/.

USEPA, 2009a. The Integrated Risk Information System (IRIS). Available at: http:// www.epa.gov/iris/index.html.

USEPA, 2009b. Technical assistance document for the reporting of daily air quality-the Air Quality Index (AQI). U.S. Environmental Protection Agency. Office of Air Quality Planning and Standards; 2009b. EPA-454/B-09-001.

USEPA, 2010. Estimation Programs Interface Suite ${ }^{\mathrm{TM}}$ for Microsoft ${ }^{\circledR}$ Windows, v 4.00 Washington, DC, USA: United States Environmental Protection Agency; 2010. Available at http://www.epa.gov/oppt/exposure/pubs/episuitedl.htm. 